\title{
The Legal Atlas $\odot$ : Map-Based Navigation and Accessibility of Legal Knowledge Sources
}

\author{
Rob Peters ${ }^{1}$ and Tom van Engers ${ }^{2}$ \\ ${ }^{1}$ Technical University Delft, The Netherlands \\ R.Peters@tbm.tudelft.nl \\ ${ }^{2}$ University of Amsterdam/ Leibniz Center for Law, The Netherlands \\ T.M.vanEngers@uva.nl
}

\begin{abstract}
For many reasons citizens, businesses and civil servants need access to regulations. The traditional approaches to provide access to these regulations are not satisfactory to these users, which have to cope with vast amounts of often interfering regulation. Normal questions like "where can I do this kind of activity" or "is this activity allowed here" are hard to answer in traditional webbased services environments. There are many attempts to create one-stop-shopfront ends to eGovernment, but these are seldom build from the perspective of the user. The Legal Atlas $(\subset$ approach offers an innovative approach, an approach that already has shown to be beneficiary to its users.
\end{abstract}

\section{Introduction}

To meet citizens demands in improving governmental (e-)services, government usually combine two approaches:

1. Deregulation, i.e. diminish the amount of rules and eliminate conflicting ones.

2. Improve accessibility, i.e. provide e-services, make the regulations transparent to citizens and businesses etc.

Knowledge about what is allowed, forbidden, permitted etc., also called 'normative knowledge', is essential for citizens and businesses when moving around in our modern society. Many citizens perceive an overkill of governmental rules, which forces them to visit multiple 'service desks' without getting many results. Furthermore finding your way in the labyrinth of rules and regulations is a challenge on its own.

Since regulatory power of the governments is based upon creating rules and enforcing them, we have strong doubts if reducing the number of regulations will ever generate sufficient results. In the constitutional system of the Netherlands e.g. there are yet over 75000 rules and despite political statements there is no limitation to this number noticeable. If we could accept that we have to deal with huge amount of rules, we can start thinking of solutions on how to cope with them.

In this paper we will show an eGovernment approach that helps citizens, businesses and civil servants to cope with a vast number of rules in their day to day decision making processes. The approach is abased upon standardized knowledge re-presentations. We advocate that the approach explained in this paper offers a powerful 
means to client satisfaction, especially when there is a strong interaction between the building blocks of central laws and local regulations. A prototype system has been build to give a proof of concept, containing state-of-the-art navigation techniques that help to find ones way among different layers of legal content. This system enables the navigation through four layers of laws and regulations, European, national, regional and municipal. Early results with using the system in the Netherlands and demonstrating it at different occasions indicate not only high user satisfaction but also feasibility in the implementation in other Europe's nations.

The three fundaments

The DTCA obtained considerable experience with in depth (legal) process automation to counter the vast consequences in the area of execution and law-enforcement when tiny changes were made to the tax laws. The University of Amsterdam and other partners were involved in the E-Power project ${ }^{1}$ and others were we elaborated upon the preliminary results from the POWER programme and applied the approach on highly 'mechanical' domains other than taxes like insurance and human resource management. One of the goals that should be achieved when applying the POWERapproach is to automate the process of adaptation to changes in the regulations. When for example a small change occurs in the laws regulating payments of insurance premium related to personnel it would save everybody a lot of trouble if the system would absorb the change, adapt the legal domain model, calculates the consequences for the execution derivates and tells the administrative apparatus of the clients where to make the adjustments in their models.

The perspective of the law being represented as a knowledge object in a set of objects (possibly implemented in a relational database environment) rather than being represented as texts as a xml-hierarchy representing article structures, became an important modelling notion leading to the Legal Atlas ${ }^{2} \odot$ approach. It would enable the client searching among local and regional laws to query legal systems comparable to querying databases. It would enable the ultimate transparency of local regulations in the sense that the citizen could ask "where can I do this?", instead of: "can I do this in place such and such?". The where-can-I-do-this query requires much more than a good website from a well-organized municipality; it requires some way standardisation of local regulations across all municipalities of a region or country. It requires the means to aggregate the legal information of all those municipalities into one system which the citizen can hold his case against. Such a eGovernment system would either require a unique coding for all local and regional legal functionalities effecting citizens or it would require a semantic mapping of the legal terms and legal procedures affecting those required functionalities of citizens. In the ideal world the system would have the advantage of both eGovernment architectures. Only in that way the client of the service could regard his case in the light of aggregated data in a way and oversee the consequences. Only that way there can be a perspective on maintainability and consistency of the ever-growing legal system as a whole.

A third field which influenced the development of the Legal Atlas $\subset$ approach was the awareness that legal content of the type regional and local law had a feature that has been neglected thus far (since almost none cross-jurisdiction knowledge-based systems have been developed); the geographical element, location or jurisdiction.

\footnotetext{
1 http://www.lri.jur.uva.nl/ epower/

2 The legal atlas was developed in the context of the ADDWIJZER project of the eContent programme
} 
This feature is getting more and more important if we model legal knowledge-based systems at European scale (because of the jurisdictions of national laws). Looking from the top of the hierarchy down, it becomes clear that European legislation and national law usually provide us with a generic set of norms while regional and local regulations add more specific rules that are applicable within a specific geographical area or context. From the perspective of the citizens it is not only vital to know which regulations are valid within their municipality or region (e.g. per zipcode); it is equally important to know exactly how a certain geographical area is governed by a certain law or set of rules. Municipalities are the local branch of eGovernment and the local regulations are the instrument to govern the actions and decisions of people in their daily lives. Those decisions and actions affect in most cases a situation "somewhere" in an area with certain constraints, rules and permissions. The Legal Atlas (C) provides access to the world of regulations through a map-view on the legislation. Such a map-based view on the law has to be powered by a different kind of software than regular content management systems and database management systems offer. It also extends functionalities normally supported by the systems used for creating technical drawings and support tasks like environmental planning (Geographical Information Systems or GIS). In the Legal Atlas( $)$ approach we make use of the main characteristics of content navigation using GIS systems, i.e. that the user can generate drawings of maps representing different features of a certain area, which overlap each other. In the case of GIS those drawings are not merely pictures represented in Jpeg or GIF format. They are dynamic database generated "maps" containing data, i.e. a set of attributes per object represented. The background against which the data-map is projected is a selection of the map of the earth on a certain zoom level. Municipalities operate at 5000-to 10,000 (i.e. scale 1:5000 to 1: 10000). Regions operate generally on 25,000 to 100,000 and country maps are 250,000 to 500,000 . It has only recently been possible to publish dynamic maps using the internet in HTML because of the size of the data files and the capacity of communication channels needed. A typical application area for the Legal Atlas $(C)$ system is urban planning where the user would e.g. "navigate" the content by interrogating the system and having feedback via a map-representation as well as more traditional representations. An example is a request for information about "industrial areas allowing for hindrance levels $>3$ " or "a planned glass house area". This type of information could be presented on a map covering multiple municipalities (probably with scale 1:25,000). For more detailed questions like the type of buildings allowed and the level of noise allowed during recreation the user could zoom in to find regulations applicable within one municipality (presented at a map with scale 1: 5000). If we want to offer this type of functionality using the internet, quite some bandwidth is required and a plug-in is need as well to manage to have reasonable response times. Especially opening different layers of data at different zoom levels is quite demanding.

\section{The Method}

For the first version of the Legal Atlas (C prototype it was chosen to first concentrate on modelling the law. For localization a unique code that indicates the regional and local areas was used. It was decided to investigate the semantic decomposition of the 
related legal texts at a later stage. This paper reflects on the early findings of the first version of the Legal Atlas $($ p prototype.

The unique regional coding scheme was developed in the DURP 3 programme in the Netherlands. DURP stands for "digital exchange of spatial plans" and its goal is to support the interoperability between different layers of government while dealing with zoning plans. The unique spatial functionality coding is based on the IMRO standard which adheres to the NEN 1878 norm for data interchange ${ }^{4}$. The Netherlands are recognised as the front runner in Europe in spatial data warehousing and standardisation according to the Inspire survey carried out in the spring of $2003^{5}$. This is not surprising if one realises that 16 million people have to share only 41.000 square $\mathrm{km}$ in that country. The innovative part of the IMRO coding is that it not only contains a system creating object-uniqueness of the spatial functionality. The coding is also legally binding: the thus coded areas on the map tell the user what is allowed and what is not allowed based on the prescription ("voorschrift"), the legal text inseparably related to that coding. The Legal Atlas $($ C makes use of this coding scheme to enable the user to query the underlying legal system using very detailed coloured maps representing legal constraints and possibilities.

The regional layers of data were provided by The Province of South-Holland ${ }^{6}$ that maintains a number of databases (Thematic Spatial Data Infrastructure) about the economy, the environment, our cultural heritage and the public infrastructure. Regional information is aggregated content by nature. For crossing different regions (especially when crossing national borders) we would need one European unique coding mechanism for those data layers and their meaning. The EUROGI initiative will hopefully reach that objective one day in the future. It has come to our attention that also other countries and regions in Europe are experimenting with the same type of legal standardisation. This indicates that European standardisation is a matter of some urgency to avoid new interoperability problems and unnecessary costs. In the Netherlands an initiative aiming at establishing at least a national standard is initiated by the IPO, the inter-provincial e-Government organisation. For the Legal Atlas (C) prototype lack of an existing standard was not too problematic, since only a limited set of regulations that didn't originate from the Province of South Holland was included in the prototype.

\section{Early Findings}

In August 2003, 8 in-depth 2 hour interviews were conducted with help from Dr. David Newman from Queens University Belfast with Notaries, building specialists, environmental specialists, legal experts and event organisers. For the purpose of the interviews a "Flat" HTML dummy prototype was build of both the back office and the user interface of the system. The purpose of the dummy was to engage into a dialogue with the interviewees based on concrete representations of the early ideas. The

3 Ministry of VROM (Spatial planning, Housing and the Environment)

4 See also www.ravi.nl

5 see also EC-Inspire commissioned by Eurostat and DG env, page 2

6 with thanks to Nienke Mier, Peter Meijer and Frits v Gulick of the Province of SouthHolland 
interviews were further supported by the definition of a set of real life scenarios or cases for which the system was meant as a helping device.

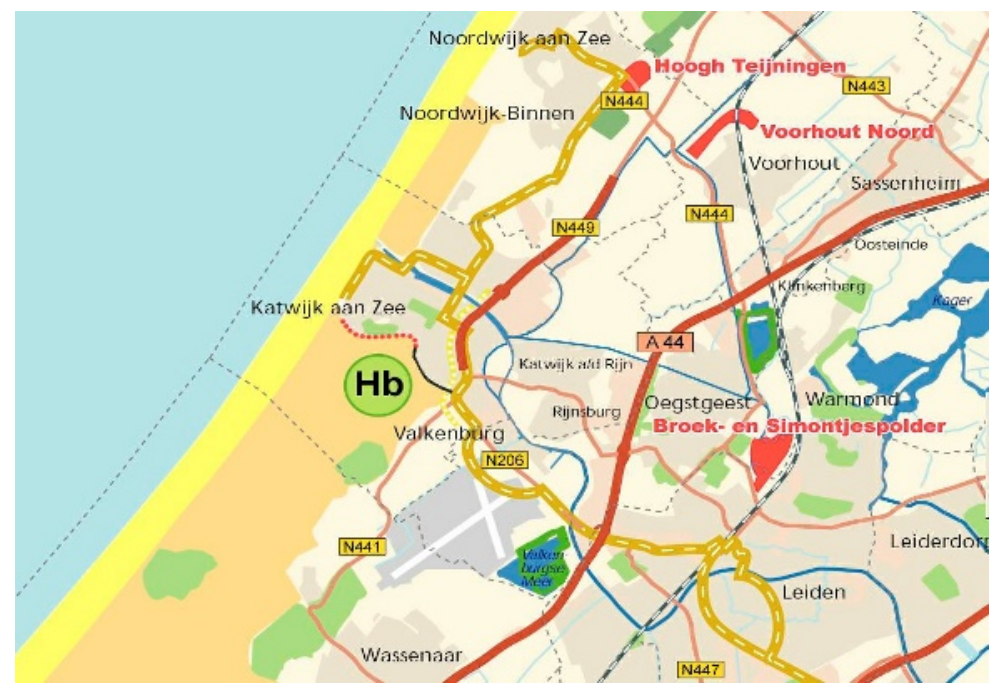

Fig. 1. Dummy map interface showing habitat area's for feed back purposes

The main results of these interviews were that the system was regarded as a potentially very beneficial and that users would like to see two additional features: more freedom of choosing relevancy of thematic map layers and more contextual data, like infrastructure and business types. The feed back encouraged the research team to build the first real dynamic prototype in the autumn of 2003. During the summer and the autumn 3.5 gigabytes of content was collected from 10 municipalities, five large infrastructural sources and the chamber of commerce to "fill" the prototype in combination with a vast amount of content obtained from the Province. This dynamic prototype proved to be a great improvement. It could for example help the citizen to establish the influence on their decision making of the Malta treaty or the Habitat legislation since their effects were displayed on a colourful map affecting a certain geographical area (see figure 1.). A text retrieval approach using e.g. Google or another text based search engine like Verity (see figure 2.) would never show the legal significance of that treaty in the same way as the Legal Atlas@ did.

\section{Technical Platform}

As the technology platform for the Legal Atlas(C) Autodesk Mapguide 6.3 was chosen, because it seemed to be the most interoperable and open family of GIS products available and it works seamlessly with the market leader ESRI. The municipalities involved recommended this platform for practical reasons like implementation and user friendliness. Mapguide does require a plug-in which can be made autodownloadable via the Autodesk website. After a number of surveys based on the con- 
siderable experience with Content Management Systems of the web company Framfab we have chosen the product "Flexiweb" of ISIS as main user interface. Flexiweb is an ASP-shell around Mapguide enabling the combination of SQL queries of legal texts in conjunction with GIS retrieval of related map objects. It took considerable time to configure the APS-shell to allow different scenarios and additional text categories.

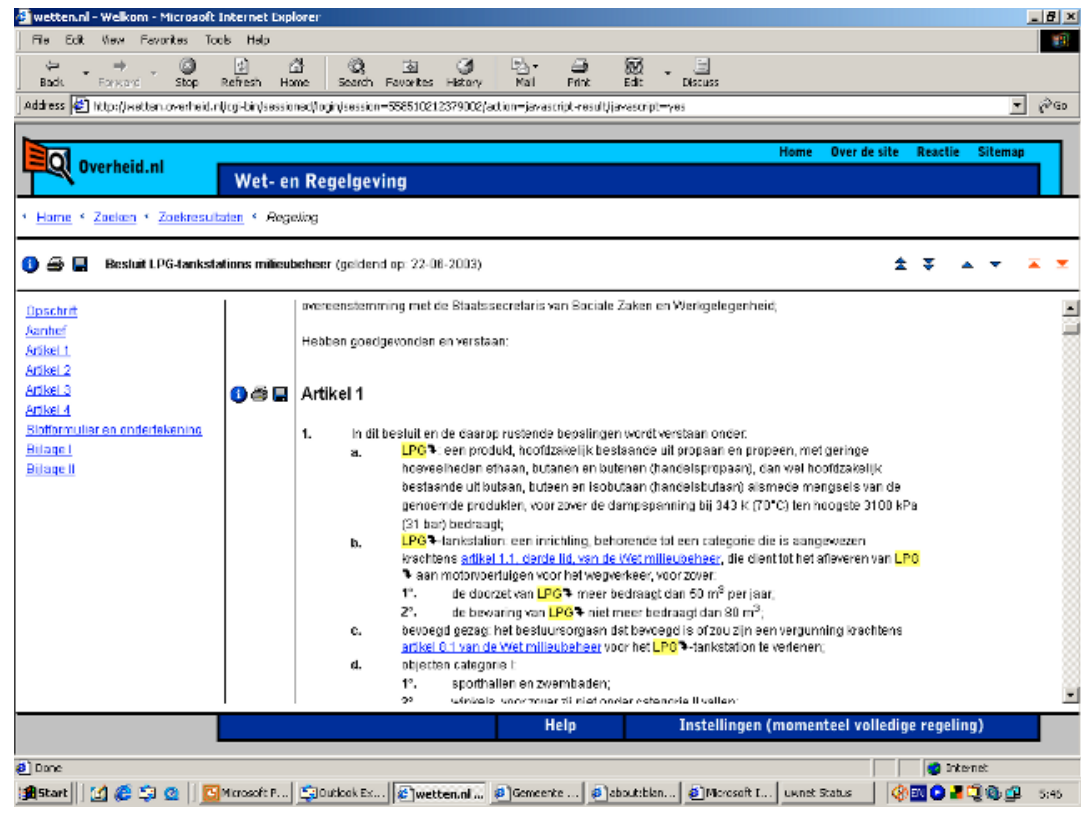

Fig. 2. Dummy text interface showing legal text related to LPG

\section{An Example of Two Types of Legal Constraints on a Map}

The Habitat legislation concerning the conservation environment and the Malta treaty legislation related to cultural heritage were translated by regional authorities into area's with a certain "value" level. Industrial area's can have a certain hindrance level attached to them. By connecting these levels with their respective legal constraints we can visualize the local implications of law application.

A number of user scenarios were defined to represent the typical decision processes where a citizen requires fast access from multiple eGovernment services to reach his goal. Figure 3 illustrates the scenario of the event organiser looking for a spot along the coastal line where he could organise a beach party involving alcoholic consumptions. The map shows the coastal line near Katwijk. The bright green area is Habitat-regulation protected and he would certainly face objections from the bird watchers there. The local Katwijk-related relevant legislation turns up the law on alcoholic drinks when queried on the keyword "alcohol". He will also be able to find out the rather strict rules on the use of soft drugs. The user now either applies for the 
required permit in Katwijk or seeks an area governed by less strict regulations. The coloured spots represent different types of economic activity obtained from the chamber of commerce like camping sites or restaurants. The bleus and other (non-bright) greens indicate planned regions for different types of natural environment preservation.

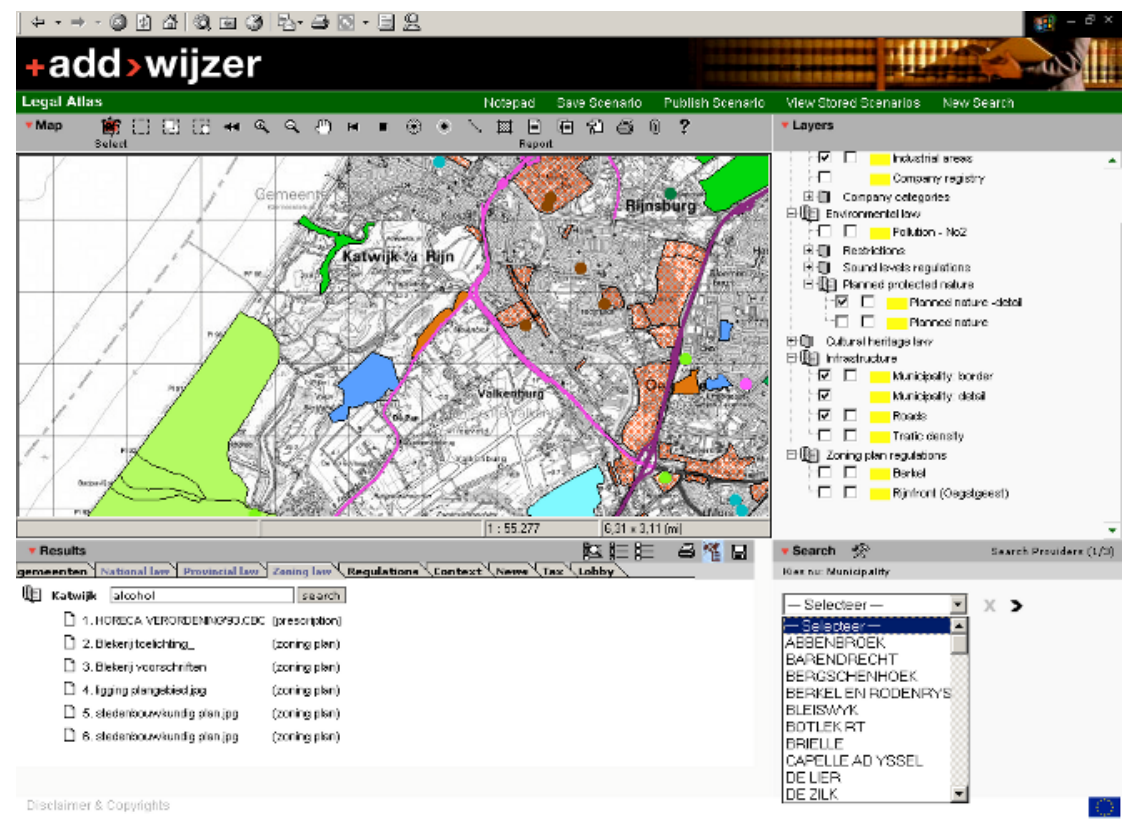

Fig. 3. Result set showing relevant legal constraints for event organisers in Katwijk

With the IMRO codification system the function of a defined area can directly be related to a law ("voorschrift") applicable in that area. Fig. 4 illustrates another legal map object representation. It highlights a selected spot in blue the central square of a neighbourhood in the city of Dordrecht as a specific area with a specific code called "c" for "centrumdoeleinden" meaning city centre purposes (coded as IMRO 310101).

The content type "habitat" in the Katwijk example is an area derived from a higher law. The centre square in the Dordrecht city example is based upon a local regulation. Both have in common that they are objects which effect can be generated and visualised from a database query.

\section{First Experiences}

The prototype has been demonstrated in November 2003 to more than twenty national delegates at the 4th meeting of the 'Group to Promote Public Sector Information (PSI)' in Luxembourg where it was received very well as an example of transparency of PSI. The prototype has also caused some major changes in the metadata strategies for local law applied by the Ministry of Internal Affairs in The Netherlands. The nine 
municipalities involved in the project thus far were also positive and decided to keep contributing content to central aggregated content hubs. They see practical value in the aggregation of the content and they liked the map-based approach to the citizen front end. A side effect of the content gathering process was the exchange of thematic content layers between governmental agencies who did not know what their neighbour had in stock. Further research with real life users outside the government should confirm the generally positive reaction to the ideas involved.

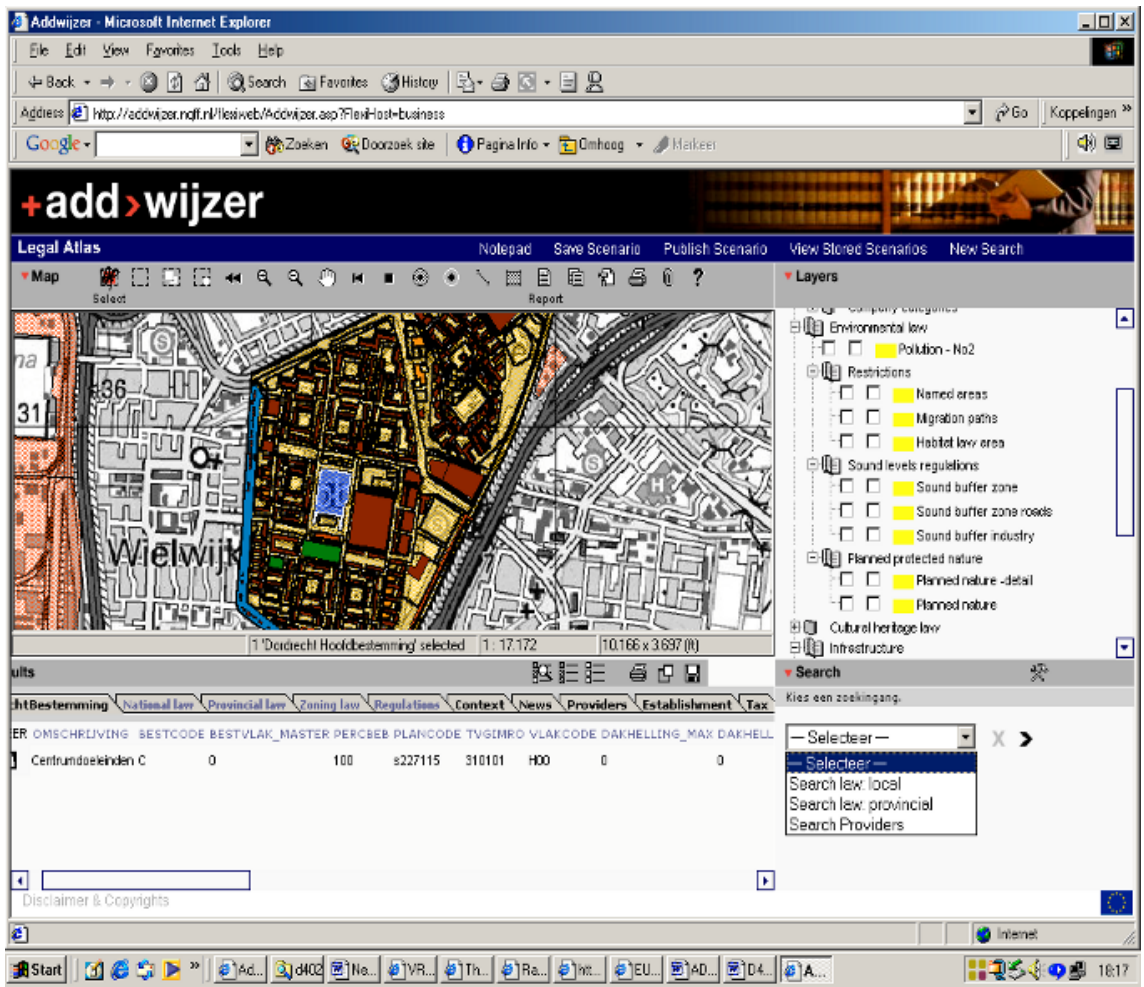

Fig. 4. Result set showing city centre purposes area in a neighbourhood in Dordrecht

\section{Conclusions}

That citizens, businesses and civil servants have to cope with vast amounts of often interfering regulations is a fact of life. The traditional approaches to provide access to these regulations are not satisfactory to these users. Normal questions like "where can I do this kind of activity" or "is this activity allowed here" are hard to answer in traditional web-based services environments. The Legal Atlas $\odot$ approach offers a completely different approach, an approach that already has shown to be beneficiary to its users. 
The Legal Atlas $(\subset$ approach combines jurisdiction-based features with geographical location and map-oriented (GIS-based) interfaces. Connecting the first two features is vital to the interoperability of the different governmental layers and therefore vital to the e-service levels of the government as a whole.

In the near future we hope to combine the semantic decomposition of the law texts with the codification that generates the legal map objects. The text governing the fact that a certain area has the legal function "city centre" and the different other legal sources containing regulations that put localized constraints could be made machine readable. This type of research is already conducted by De Maat and Van Engers (2003). The result would be that, once certain codes and processes were semantically mapped, a revision or a change of the original legal knowledge sources would automatically result in a different map for the user.

Once the processes and the semantically key concepts are mapped, we could also make maps that represent different legal sources even if they are written in different languages. Combining Dutch legal texts with German ones could for example form the basis for a map that covers the border region and could help businesses to decide were to start a new business.

Our future research will elaborate upon the current experiences with map-based access to legal sources and the E-Power production chain that helps to generate knowledge-based components from legal sources. We hope to merge these two approaches into one and test it in real life situations. We conclude in arguing that research on knowledge representations and interface layers are essential to the egovernment field. The Legal Atlas (C) approach explained in this paper is an example of a fruitful multidisciplinary research effort addressing these issues. This kind of cooperation and cross-border thinking are key elements to a successful e-Government.

\section{References}

1. EC-INSPIRE: Spatial Data Infrastructures in Europe: State of play Spring 2003 commissioned by EUROSTAT \& DGENV, K.U. Leuven

2. A. Boer and T. van Engers. A Knowledge Engineering Approach to Comparing Legislation. In Proceedings of the Conference on Knowledge Management in Government, Rhodes, Greece, 2003. Springer Verlag

3. A. Boer, T. van Engers, and R. Winkels. Using Ontologies for Comparing and Harmonizing Legislation. In Proceedings of the International Conference on Artificial Intelligence and Law (ICAIL), Edinburgh (UK), 2003. ACM Press.

4. A. Boer, R. Hoekstra, R. Winkels, T. van Engers, and F. Willaert. ${ }^{\text {META }}$ lex: Legislation in XML. In T. Bench-Capon, Aspassia Daskalopulu, and R.G.F. Winkels, editors, Legal Knowledge and Information Systems (Jurix 2002), pages 1-10, Amsterdam, 2002. IOS Press.

5. E. Glasséé, T.M. van Engers, A. Jacobs, POWER: An Integrated Method for Legislation and Regulations from their Design to their Use in E-government Services and Law Enforcement., In M-F. Moens (ed.), Digitale Wetgeving, Digital Legislation, ISBN 905958 039 7, p 175-p 204, Brugge, 2003, Die Keure.

6. E de Maat, T.M. van Engers, Mission Impossible?: Automated Norm Analysis of Legal Texts, In D. Bourcier (ed), Legal Knowledge and Information systems, Jurix2003: the sixteenth Annual conferenece, ISBN 158603398 0, Amsterdam, 2003. IOS Press 